\title{
Corrigendum
}

\section{BCL2 in breast cancer: a favourable prognostic marker across molecular subtypes and independent of adjuvant therapy received}

\begin{abstract}
S-J Dawson, N Makretsov, FM Blows, KE Driver, E Provenzano, J Le Quesne, L Baglietto, G Severi, GG Giles, CA McLean, G Callagy, AR Green, I Ellis, K Gelmon, G Turashvili, S Leung, S Aparicio, D Huntsman, C Caldas and P Pharoah
\end{abstract}

British Journal of Cancer (2010) 103, II37. doi:I0.1038/sj.bjc.660592I www.bjcancer.com

(c) 2010 Cancer Research UK

Correction to: British Journal of Cancer (2010) 103: 668-675.

The correct Table 1 is as shown here.

doi:10.1038/sj.bjc.6605736

Upon publication of the above paper in Volume 103, Issue 5, the authors noticed an error in Table 1, wherein some of the totals in the final column were incorrect.

\section{Table I}

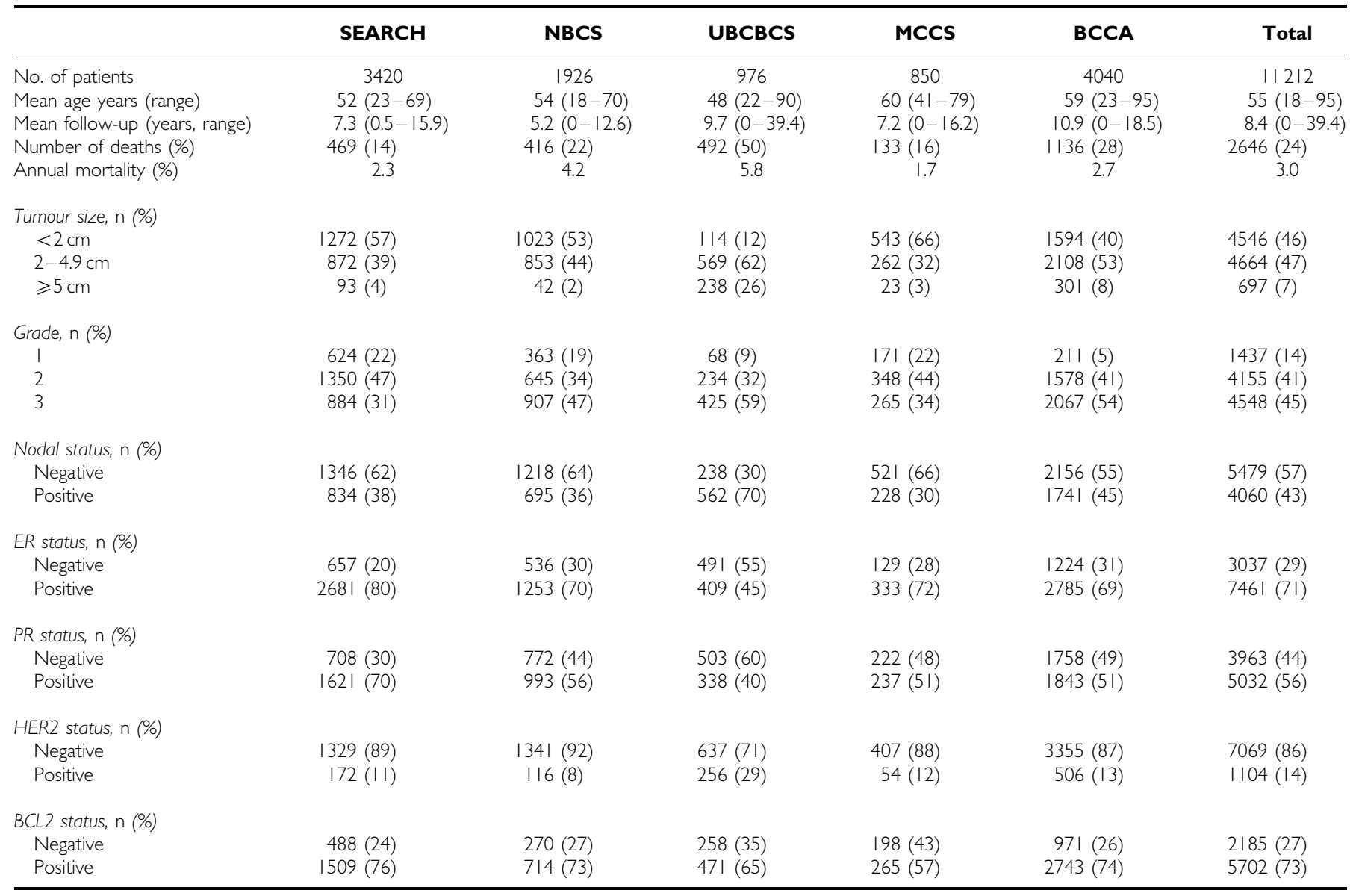

